\title{
Population viability analyses in New Zealand: a review
}

\author{
Craig E. Simpkins ${ }^{1,2,3 *}$, Finnbar Lee ${ }^{2}$, Breanna F. Powers ${ }^{2}$, Sandra Anderson ${ }^{1,2}$, Quinn Asena ${ }^{2}$, \\ James M.R. Brock ${ }^{1}$ and George L.W. Perry ${ }^{2}$ \\ ${ }^{1}$ School of Biological Sciences, University of Auckland, Private Bag 92019, Auckland, New Zealand \\ ${ }^{2}$ School of Environment, University of Auckland, Private Bag 92019, Auckland, New Zealand \\ ${ }^{3}$ Department of Ecosystem Modelling, Georg-August University of Göttingen, Büsgenweg 4, 37077, Göttingen, Germany \\ *Author for correspondence (Email: simpkinscraig063@gmail.com)
}

Published online: 22 June 2018

\begin{abstract}
Biodiversity assets often require conservation management, which, in turn, necessitates decisions about which ecosystem, community or species should be prioritised to receive resources. Population viability analysis (PVA) uses a suite of quantitative methods to estimate the likelihood of population decline and extinction for a given species, and can be used to assess a population's status, providing useful information to decision-makers. In New Zealand, a range of taxa have been analysed using the PVA approach, but the scope of its implementation has not previously been reviewed. We compiled a database of 78 published PVAs for New Zealand indigenous fauna and flora, along with details of the species considered, the data used to parametrise the model, and the technical details of their implementation. We assessed the taxa and threat status of the species for which PVA were conducted relative to the distribution of taxa across threat classes in the New Zealand Threat Classification System database. There were clear biases in the species selected for analysis, notably an over-representation of birds and threatened species in general, and an under-representation of invertebrates and plants. Model parameterisation and implementation were often not reported in a transparent or standardised way, which hinders model communication and reconstruction. To maximise the benefit of PVAs, we suggest that more attention should be given to the ecosystem-level importance of species, and to species whose threat status is changing rapidly or are not yet threatened. More clearly describing the parameterisation, underlying assumptions and implementation of PVAs will help to better contextualise their results and support reproducible ecological science and decision-making.
\end{abstract}

Keywords: biodiversity; conservation; demographic models; extinction; population dynamics; population models

\section{Introduction}

New Zealand is a global biodiversity hotspot, and this biodiversity is important ecologically, economically and culturally (Craig et al. 2000; Blaschke et al. 2013; Parliamentary Commissioner for the Environment 2016). However, since the arrival of humans in New Zealand (c. 1280 AD; Wilmshurst et al. 2008) there has been a significant loss of biodiversity, including the extinction of over 50 bird, five plant, one fish and an unknown number of herpetofauna and invertebrate species (McGlone 1989; Wilson 2004; Tennyson \& Martinson 2006; Robertson et al. 2017). These losses were largely the result of the introduction of pest species (particularly mammalian predators), habitat loss and environmental degradation (Innes et al. 2010). Due to the ongoing impacts of these and other threats, many species require active conservation management to ensure their long-term viability (Craig et al. 2000). This situation, and the ecological significance of New Zealand's biodiversity, has led to a government pledge of ongoing support for conservation in the form of the New Zealand Biodiversity Strategy (Department of Conservation 2000; Department of Conservation 2016) and nationwide initiatives such as PredatorFree New Zealand (Russell et al. 2015).

Despite such commitments, resources are limited - a common situation for conservation efforts globally (McCarthy et al. 2012). It is, therefore, important that resources are allocated in a way that maximises their usefulness. Effectively prioritising resources for the conservation of a particular species requires considering a number of criteria, including the expected cost of any management action, its predicted effectiveness, and the species' current and future risk of extinction, with the latter often carrying the most weight (Department of Conservation 2016). Currently in New Zealand, a species' risk of extinction is quantified through the New Zealand Threat Classification System developed by the Department of Conservation (DOC) (Townsend et al. 2008). This system groups species based on their population trend over 10 years or three generations (whichever is longest) of demographic data.

Some conservation biologists have raised concerns about the representativeness of the species and ecosystems that receive management interventions and, in particular, the emphasis on rare taxa (Arponen 2012; Frimpong 2018). Maximising the benefit of conservation resource expenditure requires identifying not only those species of current concern, but also those that may become of concern in the future and, importantly, understanding the processes driving changes in threat status (Sebastián-González et al. 2011; Laycock et al. 2013). The New Zealand Threat Classification System may identify common species showing a declining trend, but without further analysis the reasons for the decline will remain unknown. In some ecosystems, abundant or common taxa appear to be declining more rapidly than rare ones. For example, Inger et al. (2015) found that over the last 30 years, the European avifauna has declined in both abundance and richness, with this decline being driven by declines in more common species. Likewise, in New Zealand, Elliott et al. 
(2010) describe declines over a 30-year period in more common birds in southern beech (Nothofagaceae) forest in the Nelson Lakes National Park. Such population trends challenge the emphasis, both in terms of effort and financial investment, placed on threatened species and make it important to develop tools for assessing species' long-term dynamics and probability of persistence. One framework available to assess the sustainability and driving processes of a species or population is Population Viability Analysis (PVA) (Boyce 1992; Morris \& Doak 2002).

PVA is a structured process designed to evaluate (whether retrospectively or predictively) a species' population dynamics based on demographic data, often with the goal of estimating the probability of persistence over a specific time period(Beissinger \& Westphal 1998; Caswell 2001; Morris \& Doak 2002). Many methods have been used to develop PVAs for individual taxa, ranging from aggregated unstructured population models to stochastic individual-based simulations (Burgman 2000; Beissinger et al. 2006; Himes Boor 2014). PVAs are often used to evaluate the potential effects of change, such as response to management interventions (e.g. Elliott 1996), shifts in environmental conditions (e.g. Mitchell et al. 2010), or interactions between the two (e.g. Simpkins et al. 2015). PVAs have obvious utility for conservation management and are a component of the IUCN red-list categorisation scheme (IUCN Standards and Petitions Subcommittee 2017). Previous analyses (Brook et al. 2000; McCarthy et al. 2003) have suggested that PVAs have reasonable predictive performance so long as they are parametrised adequately given their intended purpose. PVAs are often argued to be most informative when their outcomes are interpreted in a relative rather than an absolute sense (i.e. to rank management actions rather than estimate precise quantitative outcomes)(Beissinger \& Westphal 1998). However, the quantitative information provided by PVAs may also be valuable in determining thresholds for intervention or action, rather than just stating "action $x$ will be better than action $y$ " (Ellner \& Fieberg 2003).

While PVAs are undoubtedly a useful tool for conservation decision-makers, a number of concerns exist around their potential misuse (Coulson et al. 2001; Clark \& May 2002). The predictive accuracy of PVAs is determined by both the methods employed (e.g. model type and model structure) and the data used to inform the model (quality and quantity); these need to be transparently reported for a PVA's outcomes to contribute effectively to conservation plans (Morrison et al. 2016). A global bias in conservation science research effort towards accessible and charismatic taxonomic groups with slow life-histories, predominantly birds and mammals, has been widely discussed (Clark \& May 2002; Darwall et al. 2011; Pickett et al. 2016). It is often assumed that findings from better studied taxa will act as surrogates for phylogenetically related lesser studied groups (Grenyer et al. 2006; Rodrigues \& Brooks 2007). This assumption has been questioned (Rodrigues \& Brooks 2007; Darwall et al. 2011), and if followed could lead to mismatches between where conservation efforts are focused and where they may be most beneficial.

In New Zealand, PVAs have been developed for a range of taxa in many contexts, including the evaluation of species' long-term persistence (e.g. Elliott 1996), the fate of translocated populations (e.g. Armstrong \& Ewen 2001a, 2002), the response of species to poison drops as part of predator-control operations (e.g. Armstrong \& Ewen 2001b) and species' mortality due to non-target harvesting (e.g. Francis \& Sagar 2012). Various checklists and guidelines have been published for those implementing PVAs (e.g. Morris et al. 1999; Keedwell 2004). Keedwell (2004) provides guidance on implementing PVAs specifically for the New Zealand context, highlighting the need for a clear purpose for the study (likely the most important aspect), sufficient data, and clear and adequate reporting. There has not previously been a review of how PVAs have been implemented for New Zealand taxa, and thus it is unclear whether these PVAs follow the recommendations of Keedwell (2004). Additionally, it is unclear whether the PVA studies conducted on New Zealand taxa show a taxonomic or conservation status bias (i.e. the diversity of New Zealand's biota may not be well represented). Therefore, our main objectives in this review are to: 1) assess whether New Zealand PVAs display any taxonomic or threat classification bias in their application, 2) assess the standard of model reporting and 3) provide recommendations for future PVA studies. Each of the PVAs we consider is a valuable synthesis of primary data in its own right and was carried out in a specific context; our aim is not to critique individual studies, but rather to evaluate how PVA as a practice is conducted in NZ, and how the information contained in the individual studies might be better leveraged.

\section{Methods}

\section{Literature search}

We conducted a literature search using the Google Scholar (https://scholar.google.com), Scopus (www.scopus.com) and ISI Web of Science (www.isiknowledge.com) databases. First, we used the search terms ["New Zealand" AND "population viability *"] and ["New Zealand" AND "population model *"] with the search limited to the "Environmental Science", "Agricultural and Biological Sciences", and "Earth and Planetary Sciences" subject areas. Any other published PVA studies we knew of that were not revealed by these search terms were added to the database, but we did not include unpublished theses. The publication list was filtered to include only those studies that conducted a PVA on an extant New Zealand species that is recorded in the New Zealand Threat Classification System 2007, including non-threatened species (Fig. 1, Townsend et al. 2008). We did not consider marine fish or marine invertebrates, as the majority of these species are subject to significant economic harvesting and a complete study of this factor was beyond the scope of our research. We adopted a broad definition of PVA as being a population modelling exercise where the prime concern was to evaluate the long-term dynamics of a population under some threat or in response to some perturbation. Thus, we rejected studies where the sole concern was establishing demographic vital rates in the absence of such factors (e.g. Enright \& Watson 1992). However, we did include studies where the aim was the retrospective reconstruction of population dynamics to estimate extant population size in order to assess conservation status, threat, or success of an intervention such as translocation. This process resulted in 70 studies, and 78 individual PVAs (some papers included multiple PVAs) (Appendix S1 in Supplementary Materials), involving 136 authors. Thirtynine authors contributed to multiple studies with one author contributing to 16 PVAs across 13 publications. In a number of cases multiple PVAs had been developed for the same species; we included these as separate studies. The list we compiled may not be exhaustive but we believe that it encompasses the breadth of population viability assessments conducted in New Zealand. 


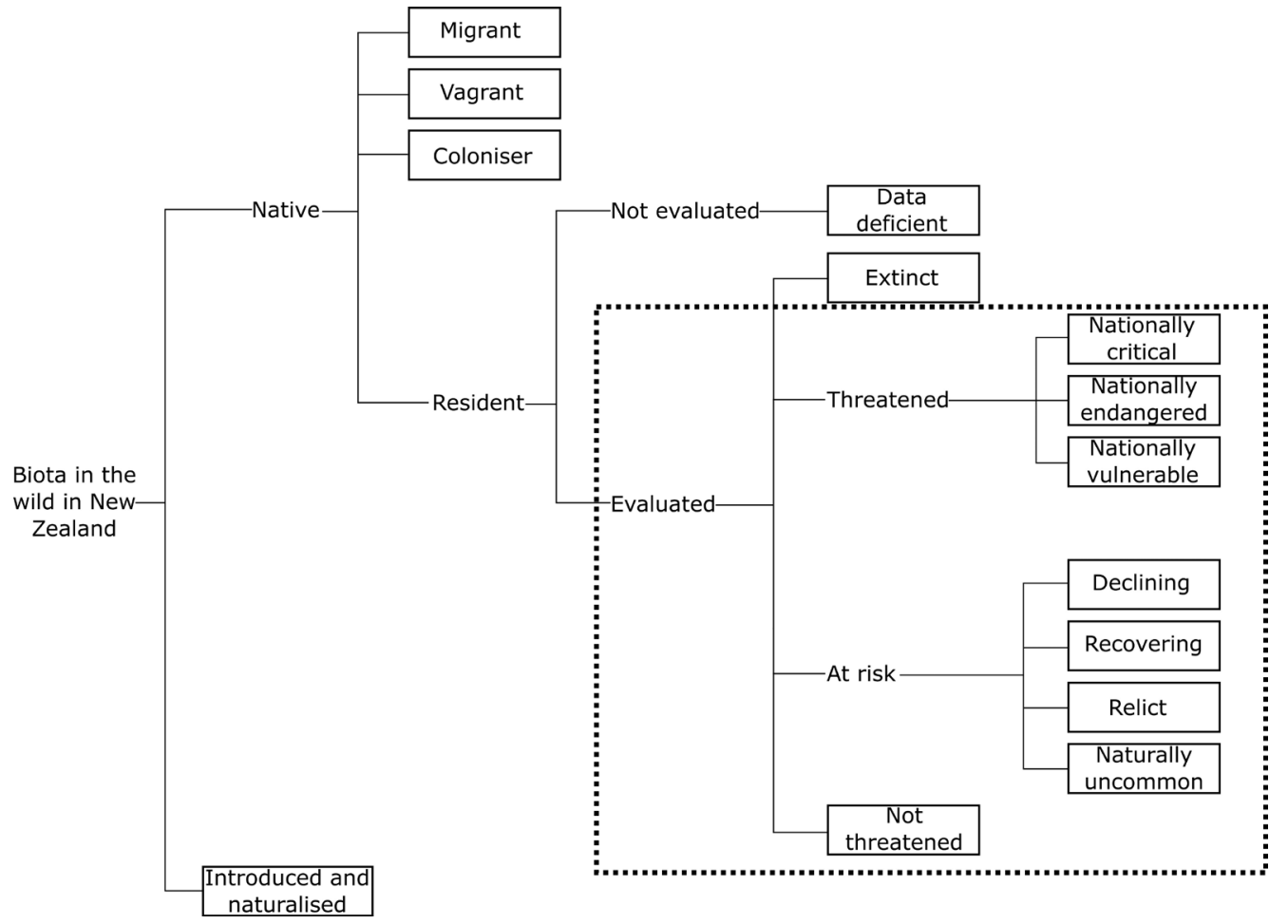

Figure 1. Structure of the New Zealand threat classification system (adapted from Townsend et al. 2008). Species included in our study identified as having a threat class falling within the dotted box.

\section{PVA Implementation and Parametrisation}

For each study that met the criteria mentioned above we recorded metadata including the publication (e.g. authors, journal), the implementation of the model (e.g. software used), the data used to parametrise the model (e.g. the timespan over which data was captured), and the species being considered. For each species we obtained information about its taxonomic group (to approximate groupings present in the New Zealand Threat Classification list), longevity (from published sources) and conservation status (Baker et al. 2016; de Lange et al. 2013; Goodman et al. 2014; Hitchmough 2013; Hitchmough et al. 2016; Newman et al. 2013; O'Donnell et al. 2017). The longevity data used in this analysis carry some uncertainty because they encompass both wild and captive populations, and the data timespan captures only the length of the sampling period not the sampling intensity. We evaluated the metadata for trends in how PVA were implemented, examining the methods applied and the nature of the data used (e.g. length of data collection relative to species longevity or projection horizon). To identify any taxonomic or threat class biases (we use the term 'bias' to mean departure from a null expectation), we used the proportional representation of taxonomic groups in the New Zealand Threat Classification as the null expectation. We assumed that if no bias was present the 78 PVAs would represent a random sample of the New Zealand Threat Classification list and, therefore, contain similar proportions of each taxonomic group. Only taxonomic groups for which at least one PVA had been published were analysed.

\section{Results and discussion}

\section{Taxonomy and threat}

Birds and mammals (both terrestrial and marine) have been the subject of the majority of PVAs (48 and 19 PVAs respectively) conducted for NZ indigenous taxa, with 57\% and $24 \%$ greater representation than expected, respectively (Fig. 2). Reptiles, fish and amphibians (6, 3 and 1 PVAs respectively) were slightly over represented $(6 \%, 2 \%$ and $1 \%$ greater representation, respectively). By contrast, plants were severely under-represented in the data, with $88 \%$ less representation than expected (1 PVA).

There was also bias in the threat classes of the species analysed (Fig. 3). Although most threat classes were overrepresented relative to the New Zealand Threat Classification List (Townsend et al. 2008), both "not threatened" (13 PVAs) and "naturally uncommon" (1 PVA) species were underrepresented, with $38 \%$ and $25 \%$ less representation, respectively. This result demonstrates an over-representation of more threatened species and an under-representation of less threatened species.

Assessment of the taxonomic grouping and threat classification of the species for which PVAs have been conducted reveals an interesting pattern in representation (Fig. 4). The most over-represented taxonomic groups, birds and (marine) mammals, differed in how they were over-represented in terms of threat classes. PVAs considering mammals were over-represented in the higher risk classes (nationally endangered and critical), while birds were over-represented in the lower risk classes (not threatened and nationally vulnerable). Five PVAs were conducted on reptiles, including for tuatara (Sphenodon punctatus) and Suter's skink (Oligosoma suteri), the only two taxa in the relict threat class in the PVA database. As only one PVA was conducted on plants (a matrix model for Beilschmiedia tawa that considered harvesting), all threat levels were under-represented; however, given the large number of plant species in the "not threatened" class (the class in which the single PVA was conducted) in the New Zealand Threat Classification List, this class was massively under-represented. Interestingly, plants were the only group, for which a PVA was found, that was under-represented. The over-representation of 

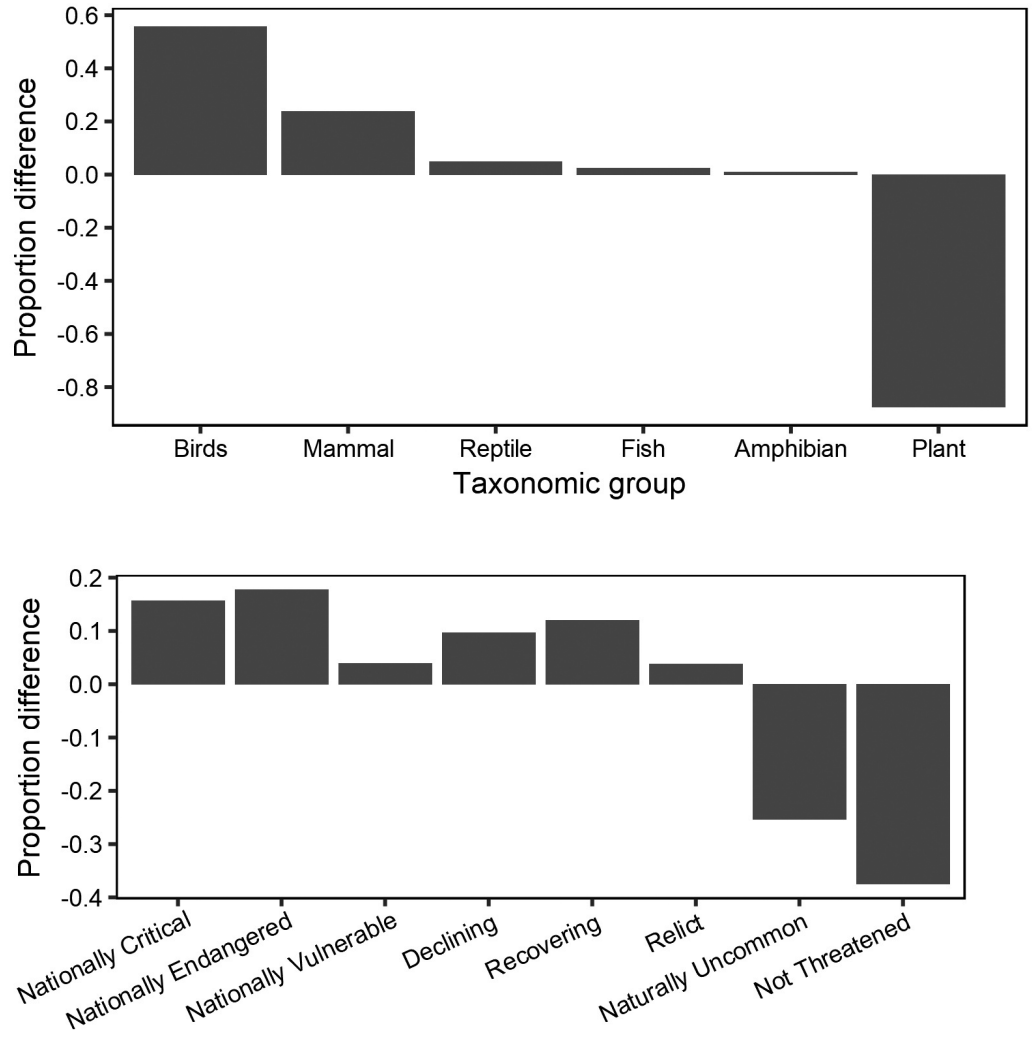

Threat class
Figure 2. Proportional representation of taxonomic groups in PVAs relative to the proportion of species in each group in the New Zealand Threat Classification List (Townsend et al. 2008) (i.e. if the difference in proportions was greater than zero, then the taxonomic group is over-represented in PVAs and vice versa).
Figure 3. Proportional representation of threat classes in PVAs relative to the proportion of species in each class in the New Zealand Threat Classification List (Townsend et al. 2008) (i.e. if the proportional difference was greater than zero, the threat class was over represented in PVAs and vice versa).

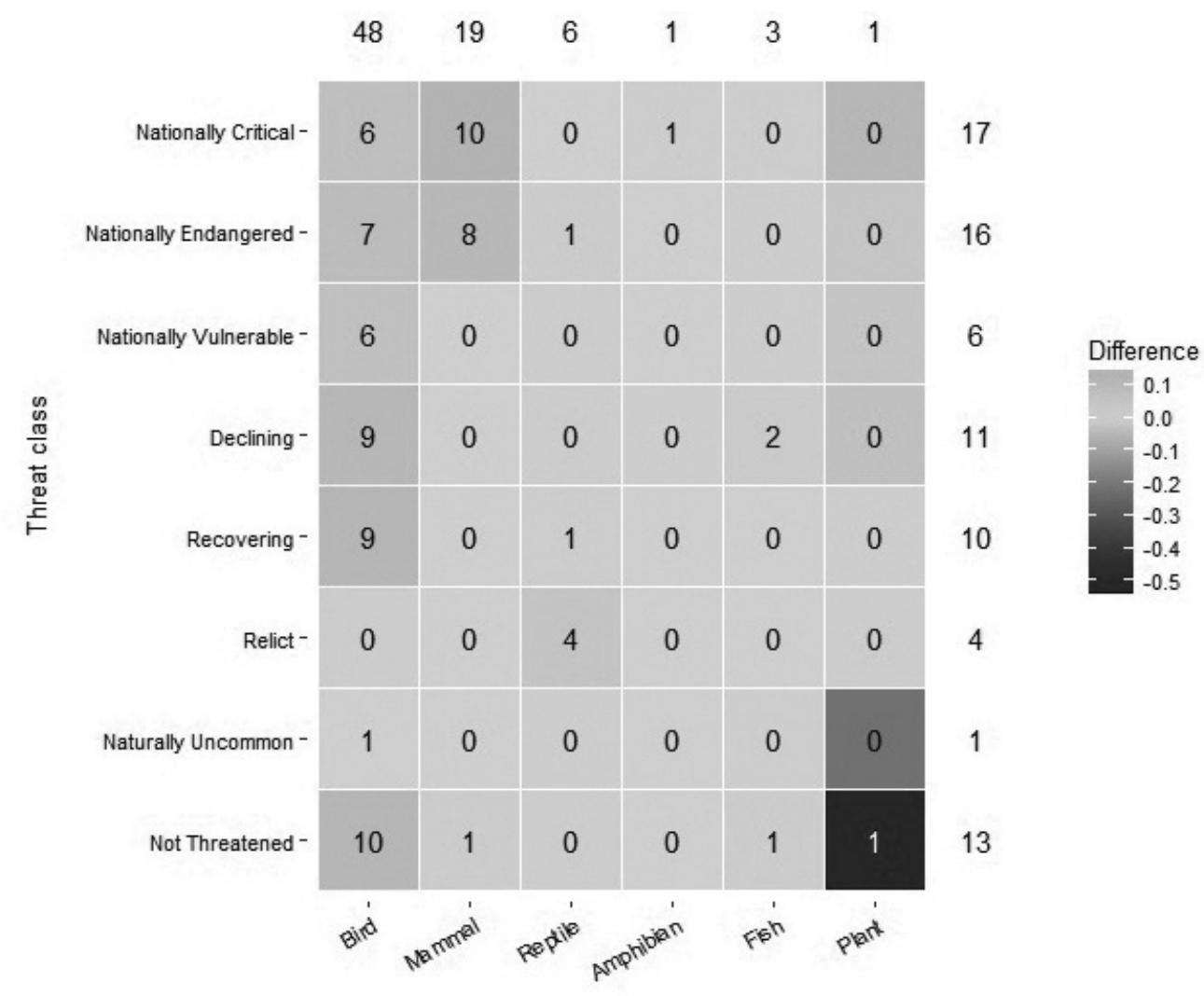

Taxonomic group

Figure 4. Difference in proportional representation between the analysed set of PVA studies and the New Zealand Threat Classification List (Townsend et al. 2008) for different taxonomic groups and threat classes. Orange denotes over-representation of the group in the analysed PVA studies, while blue signifies under-representation. The numbers contained in each cell are the number of PVA studies for that taxonomic group $\times$ threat class combination. The numbers in the top and right margins of the plot provide the total number of studies for each taxonomic group or threat class. 
most taxonomic groups is a result of these being the groups selected for studies while a large number of taxonomic groups (such as invertebrates, fungi, bryophytes) identified in the New Zealand Threat Classification List were not the subject of any PVAs, inflating the importance of individual PVAs. For example, the inclusion of a single study on amphibians resulted in an over-representation of this group as it is unlikely that any study would have been conducted based on random chance.

Overall, these results suggest that there are large differences between the species for which PVAs have been conducted in New Zealand and those listed in The New Zealand Threat Classification System database, both in terms of taxonomy and the threat class represented. As only 78 PVA studies were identified, the effect of a single PVA on any species has a significant effect on representativeness. Arguably, more charismatic species, such as the tuatara (Sphenodon spp.) and marine mammals, have been the subject of more PVAs, mirroring global trends (Clark \& May 2002). Taxa for which identification and data collection are more difficult, such as invertebrates, bryophytes and fungi, have not been included in PVAs in NZ (no published PVAs found).

Species in higher risk classes have received more attention in PVAs, again mirroring international trends in conservation science (Arponen 2012). This trend was largely driven by the high level of over-representation for at-risk mammals. This emphasis on the fate of species in higher threat classes is understandable, and we are certainly not arguing that efforts be shifted away from them. In addition, it is likely that this trend of focussing on more highly threatened species is simply a result of the necessarily reactive nature of much conservation science (Brooks et al. 2006). Threat classification systems such as the New Zealand Threat Classification List can only examine one aspect of rarity, however, identifying common species at risk of rapid population decline or extinction may require detailed, multifaceted analyses.

Although most PVAs consider just a single species, it is important to be aware of ecosystem-level interactions if we are to avoid unintended and unwanted outcomes, such as the decline of non-target species or undesirable trophic interactions (Ruscoe et al. 2011; Fedriani et al. 2016). To avoid such unexpected or perverse outcomes it is important to consider the viability of not just the target species but also the ecosystem of which it is a component (Lindenmayer et al. 2007). Realistic recovery targets for focal species should be developed with a goal that these targets, and the mechanisms used to achieve them, may enhance (or at least not harm) other native organisms in the ecosystem (Chadès et al. 2012).

\section{Model reporting}

Most of the PVAs we reviewed used some form of structured population model. The models were usually described as agestructured, but this term was used loosely and often included both stage-structured models based on ontogeny (where organisms may stay in one stage for various lengths of time) and 'true' age-structured models based solely on chronological age (see Caswell 2001). Although the division of populations into (st)age classes influences matrix model projections (Salguero Gomez \& Plotkin 2010; Regan et al. 2017), the biological rationale for the divisions were not always explicit. Methods such as integral projection, which avoids having to divide populations into arbitrary discrete classes (Ellner \& Rees 2006), were not employed by any study.

Assessing the sensitivity of a PVA to changes in parametrisation is an important aspect of model evaluation, as it highlights the parameters to which a model is disproportionately sensitive with regard to changes or uncertainty (Hamby 1994; Morris \& Doak 2002). Of the models we evaluated, 50 (64\%) conducted some form of sensitivity analysis or scenario evaluation. While a number of the studies used standard methods for sensitivity analysis such as local one-at-a-time manipulation of parameters (Drechsler 1998), others were more $a d$ hoc and few studies used more sophisticated global and multivariate methods for sensitivity assessment (e.g. Coutts \& Yokomizo 2014; Aiello-Lammens \& Akçakaya 2017). Previous reviews of the application of PVAs globally have commented on the lack of standardisation in the methods used for sensitivity analysis (Naujokaitis-Lewis et al. 2009).

The PVAs conducted for indigenous New Zealand taxa were developed using a range of different software and methods. It is critical that these methods are clearly and fully stated so that the processes represented in a particular model can be understood and the outcomes adequately contextualised (Reed et al. 2002; Naujokaitis-Lewis et al. 2009; Pe'er et al. 2013). Worryingly not all of the methods used to develop the PVAs were always reported. This is exemplified in in our finding that 28 of the reviewed studies did not report the software used to create their PVA. As different software packages often make different assumptions as to how methods should be carried out as well as being implemented differently, not including this information means that a study is not fully reproducible.

\section{Parametrisation data}

The temporal extents of the datasets used to parametrise the PVAs we considered varied between $1-6-33.7\left(5^{\text {th }}-50^{\text {th }}-95^{\text {th }}\right.$ percentile) years, although provision of this information was inconsistent and was unreported in 13 studies. The temporal extent of the data needs to be considered relative to the lifespan of the taxa of interest and the projection horizon (Zeigler et al. 2013; Rueda-Cediel et al. 2015), as well as the importance of infrequent catastrophes as determinants of population change (Ralls \& Taylor 1997). The data period:projection horizon ratio was $0.01-0.23-1.2$, meaning that in most cases the temporal extent of the data was much shorter than the period over which projections were being made. In terms of longevity, the data period:longevity ratio was $0.05-0.43-1.94$, meaning that most datasets covered a period shorter than the lifespan of the taxa of interest.

The temporal extent of the data used to parametrise the PVAs was commonly, if inconsistently, reported; however, these extents varied considerably between studies. Using data that cover relatively short timeframes is not ideal (Coulson et al. 2001); yet, this issue may not be avoidable if timely conservation interventions are to be made or long-lived taxa are being considered. Researchers, therefore, need to clearly state the limitations associated with the timeframe covered by their data. Additionally, precise quantitative predictions should be avoided when the data coverage timeframe is short, as these predictions often have been found to have low accuracy (Coulson et al. 2001).

\section{Recommendations}

Our review of the practice of PVAs in NZ suggests some potential areas for improvement that might enhance their use as decision-making tools and as ways to learn about ecological systems: 
(1) Apply PVA across a wider variety of taxa (e.g. freshwater fish, plants, invertebrates) to avoid the current taxonomic bias in the species for which PVAs are implemented in NZ. We believe this may be accomplished by increasing collaboration between researchers, particularly those working with different taxa (McAlpine et al. 2016).

(2) A continuation of studies on species with lower threat classes should be encouraged especially in taxa where these low threat class species are underrepresented (e.g. mammals). These studies should allow the processes increasing a species' vulnerability to be identified and assisting pre-emptive action to be undertaken. PVAs provide a mechanism to incorporate future risk into threat assessment when examining species which are currently not at high risk (McGowan et al. 2017). Particular attention should be paid to species whose risk classification, while still low, has relatively quickly changed in the recent past (see Roberts et al. 2016).

(3) Encourage the analysis of as broad a group of species as possible, starting with ecologically important/keystone species and species which are functionally rare within their community (Cadotte et al. 2011), to allow for greater understanding of the processes driving population change across New Zealand's biodiversity.

(4) The reporting of the data and methods used to implement individual PVAs needs to be done carefully to ensure transparency and repeatability. We suggest that researchers make use of recently created data archiving databases (e.g. COMADRE) and publicly accessible source code repositories (e.g. GitHub) to help increase transparency and repeatability (see Wood et al. 2017).

(5) PVA should be based on as long and high-quality data as possible given the context the model is being developed and used in (Coulson et al. 2001; Zeigler et al. 2013; Rueda-Cediel et al. 2015). We do not, however, advocate waiting indefinitely for the 'perfect' dataset, as not making any decision does carry a cost. Those conducting PVA need to be aware of the nature of the data they are using, use appropriate model selection and sensitivity or uncertainty analyses, and frame the outcomes of their analyses appropriately.

In many ways our recommendations echo Keedwell's (2004) checklist for a useful PVA - a clear statement of purpose, sufficient data (quality and temporal extent), a clear description of model structure and assumptions, and thorough uncertainty analyses - but extend beyond them, by providing some additional suggestions on how species are selected for study and how PVAs are described. These two areas - potential biases in species selection and the need for reproducible models - have both received considerable attention in the recent ecological and conservation biology literature. We believe that the careful application of PVAs has an important role to play in enhancing the efficiency and effectiveness of conservation in New Zealand. PVAs are a useful tool that, given data availability (often a limiting factor), are relatively straightforward to implement. In New Zealand a relatively small pool of scientists have applied PVAs across a fairly small sample of the country's biodiversity. While these studies have been highly valuable for conservation, by encouraging a wider adoption of the technique by scientists studying more species, and boosting the transparency and communication of studies, PVAs have the potential to provide insightful information that may be used to improve conservation outcomes.

\section{Acknowledgements}

The manuscript benefitted from discussions with Sarah Killick, Ben Reed, Riki Taylor, Tristan Webb and Alicia Wong. Riki Taylor drafted Fig. 1. We also thank Des Smith, Doug Armstrong and Ingrid Gruner for their comments, which greatly improved the manuscript.

\section{References}

Aiello-Lammens ME, Akçakaya HR 2017. Using global sensitivity analysis of demographic models for ecological impact assessment. Conservation Biology 31: 116-125.

Armstrong DP, Ewen JG 2001a. Assessing the value of followup translocations: a case study using New Zealand robins. Biological Conservation 101: 239-247.

Armstrong DP, Ewen JG 2001b. Estimating impacts of poison operations using mark-recapture analysis and population viability analysis: an example with New Zealand robins (Petroica australis). New Zealand Journal of Ecology 25: 29-38.

Armstrong DP, Ewen JG 2002. Dynamics and viability of a New Zealand robin population reintroduced to regenerating fragmented habitat. Conservation Biology 16: 1074-1085.

Arponen A2012. Prioritizing species for conservation planning. Biodiversity and Conservation 21: 875-893.

Baker, CS, Chilvers, BL, Childerhouse, S, Constantine R, Currey R, Mattlin R, Van Helden A, Hitchmough R, Rolfe J 2016. Conservation status of New Zealand marine mammals, 2013. New Zealand Threat Classification Series 14. Wellington, Department of Conservation. 22 p.

Beissinger SR, Westphal MI 1998. On the use of demographic models of population viability in endangered species management. Journal of Wildlife Management 62: 821-841.

Beissinger SR, Walters JR, Catanzaro DG, Smith KG, Dunning, JB, Haig SM, Noon BR, Stith BM 2006. Modeling approaches in avian conservation and the role of field biologists. Ornithological Monographs 59: 1-56.

Blaschke PM 2013. Health and wellbeing benefits of conservation in New Zealand. Science for conservation 321. Wellington, Department of Conservation. $41 \mathrm{p}$.

Brook BW, O'Grady JJ, Chapman AP, Burgman MA, Akçakaya HR, Frankham R 2000. Predictive accuracy of population viability analysis in conservation biology. Nature 404: 385-387.

Brooks TM, Mittermeier RA, Fonseca GAB da, Gerlach J, Hoffmann M, Lamoreux JF, Mittermeier CG, Pilgrim JD, Rodrigues ASL 2006. Global biodiversity conservation priorities. Science 313: 58-61.

Burgman MA 2000. Population viability analysis for bird conservation: prediction, heuristics, monitoring and psychology. Emu 100: 347-353.

Cadotte MW, Carscadden K, Mirotchnick N 2011. Beyond species: functional diversity and the maintenance of ecological processes and services. Journal of Applied Ecology 48: 1079-1087.

Caswell H 2001. Matrix population models: Construction, analysis and interpretation. 2nd edn. Sunderland, Sinauer Associates. 328 p.

Chadès I, Curtis JMR, Martin TG 2012. Setting realistic recovery targets for two interacting endangered species, sea otter and northern abalone. Conservation Biology 26: 1016-1025. 
Clark JA, May RM 2002. Taxonomic bias in conservation research. Science 297: 191-192.

Coulson T, Mace GM, Hudson E, Possingham H 2001. The use and abuse of population viability analysis. Trends in Ecology \& Evolution 16: 219-221.

Coutts SR, Yokomizo H2014. Meta-models as a straightforward approach to the sensitivity analysis of complex models. Population Ecology 56: 7-19.

Craig J, Anderson S, Clout M, Creese B, Mitchell N, Ogden J, Roberts M, Ussher G 2000. Conservation issues in New Zealand. Annual Review of Ecology and Systematics 31: 61-78.

Darwall WRT, Holland RA, Smith KG, Allen D, Brooks EGE, Katarya V, Pollock CM, Shi Y, Clausnitzer V, Cumberlidge N, Cuttelod A, Dijkstra K-DB, Diop MD, García N, Seddon MB, Skelton PH, Snoeks J, Tweddle D, Vié J-C 2011. Implications of bias in conservation research and investment for freshwater species. Conservation Letters 4: 474-482.

de Lange P, Rolfe J, Champion P, Courtney S, Heenan P, Barkla J, Cameron E, Norton D, Hitchmough R 2013 Conservation status of New Zealand indigenous vascular plants 2012. New Zealand Threat Classification Series 3. Wellington, Department of Conservation. $74 \mathrm{p}$.

Department of Conservation 2000. New Zealand biodiversity strategy 2000-2020. Wellington, Department of Conservation New Zealand. 144 p.

Department of Conservation 2016. New Zealand biodiversity action plan 2016-2020. Wellington, Department of Conservation New Zealand. 60 p.

Drechsler M 1998. Sensitivity analysis of complex models. Biological Conservation 86: 401-412.

Elliott GP 1996. Mohua and stoats: A population viability analysis. New Zealand Journal of Zoology 23: 239-247.

Elliott GP, Wilson PR, Taylor RH, Beggs JR 2010. Declines in common, widespread native birds in a mature temperate forest. Biological Conservation 143: 2119-2126.

Ellner SP, Fieberg J 2003. Using PVA for management despite uncertainty: Effects of habitat, hatcheries, and harvest on salmon. Ecology 84: 1359-1369.

Ellner SP, Rees M 2006. Integral projection models for species with complex demography. The American Naturalist 167: 410-428.

Enright NJ, Watson AD 1992. Population dynamics of the nikau palm Rhopalostylis sapida in a temperate rainforest remnant near Auckland, New Zealand. New Zealand Journal of Botany 30: 29-43.

Fedriani JM, García LV, Sánchez ME, Calderón J, Ramo C 2016. Long-term impact of protected colonial birds on a jeopardized cork oak population: conservation bias leads to restoration failure. Journal of Applied Ecology 54: 450-458.

Francis RIC, Sagar PM 2012. Modelling the effect of fishing on southern Buller's albatross using a 60-year dataset. New Zealand Journal of Zoology 39: 3-17.

Frimpong EA 2018. A case for conserving common species. PLOS Biology 16: e2004261.

Goodman JM, Dunn NR, Ravenscroft PJ, Allibone RM, Boubee JAT, David BO, Griffiths M, Ling N, Hitchmough RA, Rolfe JR 2014. Conservation status of New Zealand freshwater fish, 2013. New Zealand Threat Classification Series 7. Wellington, Department of Conservation. $16 \mathrm{p}$.

Grenyer R, Orme CDL, Jackson SF, Thomas GH, Davies RG, Davies TJ, Jones KE, Olson VA, Ridgely RS, Rasmussen
PC, Ding T-S, Bennett PM, Blackburn TM, Gaston KJ, Gittleman JL, Owens IPF 2006. Global distribution and conservation of rare and threatened vertebrates. Nature. 444: 93-96.

Hamby DM 1994. A review of techniques for parameter sensitivityanalysisofenvironmentalmodels. Environmental Monitoring and Assessment 32: 135-154.

Himes Boor GK 2014. A framework for developing objective and measurable recovery criteria for threatened and endangered species. Conservation Biology 28: 33-43.

Hitchmough R 2013. Summary of changes to the conservation status of taxa in the 2008-11 New Zealand Threat Classification System listing cycle. New Zealand Threat Classification Series 1. Wellington, Department of Conservation. $24 \mathrm{p}$.

Hitchmough R, Barr B, Lettink M, Monks J, Reardon J, Tocher M, van Winkel D, Rolfe J 2016. Conservation status of New Zealand reptiles, 2015. New Zealand Threat Classification Series 17. Wellington, Department of Conservation. $18 \mathrm{p}$.

Inger R, Gregory R, Duffy JP, Stott I, Voříšek P, Gaston KJ 2015. Common European birds are declining rapidly while less abundant species' numbers are rising. Ecology Letters 18: 28-36.

Innes J, Kelly D, Overton JM, Gillies C 2010. Predation and other factors currently limiting New Zealand forest birds. New Zealand Journal of Ecology 34: 86-114.

IUCN Standards and Petitions Subcommittee. 2017. Guidelines for using the IUCN Red List categories and criteria. Version 13. IUCN. Downloaded from http://www.iucnredlist.org/ documents/RedListGuidelines.pdf.

Keedwell RJ 2004. Use of population viability analysis in conservation management in New Zealand. Science for Conservation 243. Wellington, Department of Conservation New Zealand. 60 p.

Laycock HF, Moran D, Raffaelli DG, White PCL 2013. Biological and operational determinants of the effectiveness and efficiency of biodiversity conservation programs. Wildlife Research 40: 142-152.

McAlpine C, Catterall CP, Nally RM, Lindenmayer D, Reid JL, Holl KD, Bennett AF, Runting RK, Wilson K, Hobbs RJ, Seabrook L, Cunningham S, Moilanen A, Maron M, Shoo L, Lunt I, Vesk P, Rumpff L, Martin TG, Thomson J, Possingham H 2016. Integrating plant- and animal-based perspectives for more effective restoration of biodiversity. Frontiers in Ecology and the Environment 14: 37-45.

McCarthy MA, Andelman SJ, Possingham HP 2003. Reliability of relative predictions in population viability analysis. Conservation Biology 17: 982-989.

McCarthy DP, Donald PF, Scharlemann JPW, Buchanan GM, Balmford A, Green JMH, Bennun LA, Burgess ND, Fishpool LDC, Garnett ST, Leonard DL, Maloney RF, Morling P, Schaefer HM, Symes A, Wiedenfeld DA, Butchart SHM 2012. Financial costs of meeting global biodiversity conservation targets: current spending and unmet needs. Science 338: 946-949.

McGlone MS 1989. The Polynesian settlement of New Zealand in relation to environmental and biotic changes. New Zealand Journal of Ecology 12: 115-S129.

McGowan CP, Allan N, Servoss J, Hedwall S, Wooldridge B 2017. Incorporating population viability models into species status assessment and listing decisions under the U.S. Endangered Species Act. Global Ecology and Conservation 12: 119-130. 
Mitchell NJ, AllendorfFW, Keall SN, Daugherty CH, Nelson NJ 2010. Demographic effects of temperature-dependent sex determination: will tuatara survive global warming? Global Change Biology 16: 60-72.

Morris WF, Doak DF 2002. Quantitative conservation biology: Theory and practise of population viability analysis. Massachusetts, Sinauer Associates Inc. 480 p.

Morris WF, Doak DF, Groom M, Kareiva PM, Fieberg J, Gerber L, Murphy P, Thomson D 1999. A practical handbook for population viability analysis. Arlington, The Nature Conservancy.

Morrison C, Wardle C, Castley JG 2016. Repeatability and reproducibility of population viability analysis (PVA) and the implications for threatened species management. Frontiers in Ecology and Evolution 4: 98.

Naujokaitis-Lewis IR, Curtis JMR, Arcese P, Rosenfeld J 2009. Sensitivity analyses of spatial population viability analysis models for species at risk and habitat conservation planning. Conservation Biology 23: 225-229.

Newman D, Bell B, Bishop P, Burns R, Haigh A, Hitchmough R 2013. Conservation status of New Zealand frogs, 2013. New Zealand Threat Classification Series 5. Wellington, Department of Conservation. $14 \mathrm{p}$.

O’Donnell CFJ, Borkin KM, Christie JE, Lloyd B, Parsons S, Hitchmough RA2017. Conservation status of New Zealand bats, 2017. New Zealand Threat Classification Series 21. Wellington, Department of Conservation. 8 p.

Parliamentary Commissioner for the Environment. 2016. The state of New Zealand's environment. Wellington, Parliamentary Commissioner for the Environment.

Pe'er G, Matsinos YG, Johst K, Franz KW, Turlure C, Radchuk V, Malinowska AH, Curtis JMR, Naujokaitis-Lewis I, Wintle BA, Henle K 2013. A protocol for better design, application, and communication of population viability analyses. Conservation Biology 27: 644-656.

Pickett EJ, Stockwell MP, Clulow J, Mahony MJ 2016. Modelling the population viability of a threatened amphibian with a fast life-history. Aquatic Conservation: Marine and Freshwater Ecosystem 26: 9-19.

Ralls K, Taylor BL 1997. How viable is population viability analysis? In: Pickett STA, Ostfeld RS, Shachak M, Likens GE eds. The ecological basis of conservation. Boston, Springer. Pp. 228-235.

Reed JM, Mills LS, Dunning Jr. JB, Menges ES, McKelvey KS, Frye R, Beissinger SR, Anstett M-C, Miller P 2002. Emerging issues in population viability analysis. Conservation Biology 16: 7-19.

Regan HM, Bohórquez CI, Keith DA, Regan TJ, Anderson KE 2017. Implications of different population model structures for management of threatened plants. Conservation Biology 31: 459-468.

Roberts BEI, Harris WE, Hilton GM, Marsden SJ 2016. Taxonomic and geographic bias in conservation biology research: A systematic review of wildfowl demography studies. PLOS ONE 11: e0153908.

Robertson HA, Baird K, Dowding JE, Elliott GP, Hitchmough RA, Miskelly CM, McArthur N, O’Donnell CFJ, Sagar

Received 7 November 2017; accepted 28 May 2018

Editorial board member: Des Smith; Acting Editor: Jo Monks
PM, Scofield PR; Taylor GA 2016. Conservation status of New Zealand birds, 2016. New Zealand Threat Classification Series 19. Wellington, Department of Conservation. 27 p.

Robinson OJ, Lockwood JL, Stringham OC, Fefferman NH 2015. A novel tool for making policy recommendations based on PVA: helping theory become practice. Conservation Letters 8: 190-198.

Rodrigues ASL, Brooks TM 2007. Shortcuts for biodiversity conservation planning: The effectiveness of surrogates. Annual Review of Ecology, Evolution, and Systematics 38: 713-737.

Rueda-Cediel P, Anderson KE, Regan TJ, Franklin J, Regan HM 2015. Combined influences of model choice, data quality, and data quantity when estimating population trends. PLOS ONE 10: e0132255.

Ruscoe WA, Ramsey DSL, Pech RP, Sweetapple PJ, Yockney I, Barron MC, Perry M, Nugent G, Carran R, Warne R, Brausch C, Duncan RP2011. Unexpected consequences of control: competitive vs. predator release in a four-species assemblage of invasive mammals. Ecology Letters 14: 1035-1042.

Russell JC, Innes JG, Brown PH, Byrom AE 2015. Predatorfree New Zealand: conservation country. BioScience 65: $520-525$.

Salguero Gomez R, Plotkin JB 2010. Matrix dimensions bias demographic inferences: implications for comparative plant demography. The American Naturalist 176: 710-722.

Sebastián-GonzálezE, Sánchez-Zapata JA, Botella F, Figuerola J, Hiraldo F, Wintle BA 2011. Linking cost efficiency evaluation with population viability analysis to prioritize wetland bird conservation actions. Biological Conservation 144: 2354-2361.

Simpkins C, Perry GLW, Glaser A, Allerby T, Dennis TE 2015. Effects of predation by introduced mammals and mortality due to severe floods on population viability of the endangered Blue Duck(Hymenolaimus malacorhynchos). Emu 115: 146-157.

Tennyson AJD, Martinson P 2006. Extinct birds of New Zealand. Wellington, Te Papa Press. 140 p.

Townsend AJ, de Lange PJ, Duffy CAJ, Miskelley CM, Molloy J, Norton DA 2008. New Zealand threat classification system manual. Wellington, Department of Conservation. $36 \mathrm{p}$.

Wilmshurst JM, Anderson AJ, Higham TGF, Worthy TH 2008. Dating the late prehistoric dispersal of Polynesians to New Zealand using the commensal Pacific rat. Proceedings of the National Academy of Sciences 105: 7676-7680.

Wilson K-J 2004. Flight of the Huia: Ecology and conservation of New Zealand's frogs, reptiles, birds, and mammals. Christchurch, Canterbury University Press. 411 p.

Wood KA, Stillman RA, Hilton GM 2017. Conservation in a changing world needs predictive models. Animal Conservation 87-88.

Zeigler SL, Che-Castaldo JP, Neel MC 2013. Actual and potential use of population viability analyses in recovery of plant species listed under the U.S. Endangered Species Act. Conservation Biology 27: 1265-1278. 


\section{Supplementary Material}

Additional supporting information may be found in the online version of this article:

Appendix S1. List of PVA studies analysed, including citations, the focal species of the study and its threat class, and a brief description of the purpose of the PVA in each study.

The New Zealand Journal of Ecology provides online supporting information supplied by the authors where this may assist readers. Such materials are peer-reviewed and copy-edited but any issues relating to this information (other than missing files) should be addressed to the authors. 